\title{
Counseling Update: A Flexible Monitoring Method for the Client and Practitioner
}

\author{
David Freiband \\ Srinika Jayaratne \\ University of Michigan \\ Eugene Talsma \\ Charles Tommasulo \\ Family Service Agency of Genessee County, Flint, MI
}

\begin{abstract}
Recent years have seen a number of articles questioning both the utility and practicality of single-case designs. The authors propose a flexible monitoring method for practice evaluation. The proposed method is presented as a dynamic model, one that utilizes the existing evaluative procedures of the practitioner. This flexible method is proposed within the general outlines of developmental research. It is proposed as a method designed to lead practitioners toward an empirical model of practice. Some case examples are provided to substantiate the utility and value of the model.
\end{abstract}

Before the 1970s, researchers and clinicians had little empirical research to document the effectiveness of social work interventions. Rather, such interventions were assumed to be effective (Blythe \& Briar, 1985). Since the 1970 s, single-case designs have been promoted as the desired methodology for the evaluation of practice (Bloom \& Fischer, 1982; Howe, 1974; Jayaratne \& Levy, 1979; Thomas, 1975). This model of practice evaluation was introduced within the rubric of empirical clinical practice. Originally adopted by behavioral researchers in education and psychology, this approach to practice evaluation was depicted as a means of addressing concerns about monitoring and improving the efficacy of practice and has been promoted and utilized most actively in the field of social work by researchers

Authors'Note: We would like to thank the following employees of the Family Service Agency of Genessee County for their assistance in undertaking this project: Tammy Burgess, Ruth Miller-Yoder, Dorothy Latchana, Kathy Laux, Darcy Morroso, Michael Niemi, Frank Scott, Michael Torres, and Mark Word. Correspondence may be addressed to Srinika Jayaratne, School of Social Work, University of Michigan, Ann Arbor, MI 48109.

Research on Social Work Practice, Vol. 3 No. 2, April 1993 155-174

C 1993 Sage Publications, Inc. 
and educators (e.g., Bloom \& Fischer, 1982; Blythe \& Briar, 1985; Briar, 1977; Robinson, Bronson, \& Blythe, 1988).

Although several authors have described the merits of using single-case evaluation in clinical social work (e.g., Levy \& Olsen, 1979; Tripodi \& Epstein, 1980; Wodarski, 1981) and although many graduate courses now introduce students to this methodology, it appears to have received limited use in practice settings (Dolan \& Vourlekis, 1983; Gingerich, 1984; Mutschler, 1984; Richey, Blythe, \& Berlin, 1987; Welch, 1983). Richey et al. (1987) point out, however, that this nonacceptance does not appear to be a rejection of the methodology per se, nor does it represent a wholesale rejection of practice evaluation. Indeed, many practitioners incorporate activities that constitute parts of the single-case methodology, such as the specification of problems, goals, and interventions, but few practitioners are likely to gather systematic data or baseline information (Gingerich, 1984; Mutschler, 1984).

In examining the reasons for the lack of implementation of single-case methodology, Robinson et al. (1988) argue that the situation resembles one related to the innovation of a new product. Single-case methodology, for all intents and purposes, is an innovation in the practice arena. It demands a different set of behaviors and practice procedures from the worker. Therefore, Robinson et al. (1988) suggest that those factors related to innovation diffusion are an inherent issue in the dissemination of this methodology. Thus factors related to the design process, the degree of development of the innovation, its adequacy and preparedness, the relative costs and benefits, the user's attitude toward the innovation, the availability of organizational supports, and evidence of adoption of the innovation by esteemed professionals would all become key variables in the decision to adopt or not adopt this innovation (e.g., Campbell, 1988; Mutschler, 1984; Rothman, 1980; Thomas, 1978).

Historically, research dictums have guided practice evaluation endeavors. Some asserted that practitioners should integrate single-case methodology into their practice and, thus, become practitioner-researchers (Blythe \& Briar, 1985; Briar, 1977; Jayaratne \& Levy, 1979). These pronouncements often met with antagonism and debate (e.g., Heineman, 1981; Kagle, 1983; Witkin, 1991). Most arguments against this perspective centered on two major ideas. First, practitioners argued that practice was an "art," something that was difficult to capture or specify, let alone measure. Furthermore, there was a strong belief that the empirical practice regimen was based on a behavioral paradigm, and although it may be feasible within that theoretical model, it was less useful in any other (Nelsen, 1981; Saleeby, 1979). Witkin (1991) 
and others have pushed this perspective even further and proposed that the positivist paradigm of the empirical model is simply inappropriate for practice evaluation. The second argument arose from within the researchers. Thomas (1978) noted that the objectives of research were very different from the objectives of practice, and often in conflict. Other researchers disagreed (Conte \& Levy, 1980; Gambrill \& Barth, 1980) and argued that good practice is equivalent to good research.

This debate led Gingerich (1990) to clarify further the distinction between practice research and practice evaluation. The basic stance taken by Gingerich is that "practice requires evaluation, not research." In making the distinction, Gingerich notes that the purpose of research is to develop scientific knowledge, whereas the purpose of evaluation is to determine whether or not a particular outcome was achieved (see, also Barlow, Hayes, \& Nelson, 1984; Thomas, 1978). Although one could debate the merits of this distinction, the issue will not be settled by researchers alone. We assume that practitioners do assess and evaluate their practice. We further assume that these assessments and evaluations provide an important basis upon which the practitioner makes decisions regarding the continuation of treatment, alteration of treatment plans, or termination of an intervention.

When this scenario is placed in perspective, one critical feature stands out. It would seem that the research community thus far may have overlooked the utility of social work's age-old advice to workers: "Start where the client is." Researchers have tended to guide the practice research agenda while allowing workers little input. This "oversight," in our opinion, has resulted in alienating workers and is the weak link in the application of relevant research principles to the practice arena. Thus we need to reassess our agenda with regard to practice evaluation and practice research by beginning to study how workers actually evaluate progress with their clients. By beginning to understand how workers make judgments about the relative effectiveness of their services, we may be in a position to develop better evaluation and research designs. By beginning to understand what kinds of criteria workers bring to bear on their assessments of relative success or failure, we may be in a better position to develop clinically relevant measurement tools. By beginning to understand the sources of information that workers use in their assessments, we may be in a better position to identify who is involved in this decision and, thereby, be able to design more pertinent measurement strategies.

This perspective views the researcher as one partner in a cooperative venture. The workers, clients, agency administrators, and possibly other interested parties constitute the "group" that ultimately will have a say in the character of practice evaluation. What these separate parties or stakeholders 
have to say will not only affect the process of outcome evaluation, it will also help define what is meant by a desirable outcome (Jayaratne, 1991; Tripodi, 1991). A stakeholder-focused evaluation will (a) answer the questions of central concern to the client, (b) establish a sense of ownership in the client, and (c) maintain the client's investment in the findings (Gill \& Zimmerman, 1990). It is in this context that we are proposing the Counseling Update as a client-practitioner method of monitoring.

\section{THE CLIENT-PRACTITIONER METHOD OF MONITORING}

The client-practitioner evaluative method is a flexible and dynamic model of evaluation. The model we are proposing is an inductive one, in which one attempts to make some sense of what is, without imposing external constraints. Practitioners do make interventions and judge the results of their interventions. The criteria employed by practitioners in these judgments often change over time as a result of additional information gathered during the course of treatment. From these observations would emerge more general models that are then used by the worker to assess overall client change. This perspective is compatible with what Stake (1975) calls "responsive evaluation." In conducting responsive evaluation, one inevitably "trades off some measurement precision in order to increase the usefulness of the findings to persons in and around the program" (p. 14). Thus one may have to forgo the use of reliable and valid instrumentation to achieve "treatment utility" (Hayes, Nelson, \& Jarrett, 1987; Thyer, 1991). As Kirk (1986) points out, measuring concepts allow us a common language for discourse, "but concepts can also be reified, distorting our thinking, capturing realities that don't exist and lulling us into a false sense of enlightenment" (p. 194).

The client-practitioner method offers an alternative that we hope will ultimately lead to instrumentation and methodology useful for workers, supervisors, administrators, and researchers. Our approach utilizes a stepwise model and shaping process reflective of developmental research (Thomas, 1984). According to Thomas (1990), "Developmental practice is conceived of as a mode of practice in which the practitioner is also the developer of interventions" (p. 208). Over time, with repeated applications and refinements, a more clinically valid and reliable procedure would emerge. Although idiosyncrasy may remain an unalterable feature, systematization, along with the possibility of transferring this information to others, will, we hope, be the long-term benefit of this developmental approach. 
The defined purpose is twofold: First, we aim to develop an evaluative framework based on existing and idiosyncratic methods of evaluation used by practitioners. Thus "data may, in large part, be viewed as a description of practitioners' perceptions" (Witkin, 1991, p. 162). In this way, measurement is integrated with service delivery, rather than measurement being separated from service delivery (Patton, 1986). Second, we wish to develop a training and supervisory mechanism based on the gathering of systematic and idiosyncratic data. In doing this, we are far less concerned with issues of research, such as bias and validity. For example, a worker may assess the degree of marital satisfaction in marital treatment or the level of depression with a depressed client. For the researcher, these assessments must also be reliable and valid. Although this would also hold true for the practitioner, it is less a question of statistics and methodology and more an issue of clinical relevance.

Inherent in this approach are the weaknesses associated with subjective and idiosyncratic modes of judgment and assessment. These types of subjective evaluations, however, may have high face validity, in that they represent the "most accurate portrayal of the circumstances, thoughts, and feelings" (Bloom \& Fischer, 1982, p. 169). But, by their very nature, these evaluative approaches are susceptible to measurement reactivity and related issues of diminished reliability and validity. Within the confines of developmental research, however, this procedure has high "usability," that is, the procedure is relevant, simple, inexpensive, and flexible (Thomas, 1984).

Our overarching goal is to help practitioners define, clarify, and systematize their methods of practice evaluation. It is our contention that the achievement of systematic data collection is a first step in the direction of more stringent and scientific modes of practice research and evaluation. It is this potential movement from an inductive evaluation mode to a deductive research approach to evaluation that characterizes the flexible paradigm model. We do not believe that the "scientific imperative" is obsolete (Heineman, 1981; Witkin, 1991); rather, we need to rethink its application.

In this context, we accept the five elements of fourth-generation evaluation proposed by Guba and Lincoln (1989). Here, the concerns and issues of the stakeholders, the primary constituents in treatment, provide the major foci for evaluation; the stakeholders in this instance are the agency, the worker, the client, and significant others.

1. Stakeholders are always at risk. By definition, both workers and clients have much at stake in a treatment program. The worker may be at risk of being judged unfairly by researchers and critically by clients, supervisors, and co-workers. Similarly, a client may be at risk of losing his or her power 
and control over life circumstances. The risk can be minimized by allowing both parties a vested interest in the process of evaluation. Such a process may not only result in empowering the client, it would also bring into play the consumer satisfaction aspects of service delivery (Russell, 1990). The agency, in turn, may benefit from direct feedback from its clients and workers in its own programmatic assessments.

2. Stakeholders may be disenfranchised and made powerless. Evaluation produces information, and information is power (Brunner \& Guzman, 1989). If a researcher employed valid and reliable tools that have little meaning to the client, a tangential meaning to the practitioner, and data for the researcher and agency, the power of the information lies primarily with the latter. Similarly, if only the worker evaluates the treatment outcome, the client is disenfranchised. As Larsen, Attkisson, Hargreaves, and Ngyen (1979) point out, any evaluation that omits the client is potentially biased and logically incomplete and renders the client powerless. The treatment situation can be made more equitable by having workers and clients engage in evaluative strategies that are understandable to both parties and useful to the process of treatment.

3. Stakeholders use evaluative information. That there is constant and ongoing assessment of clinical progress by both the worker and client is a given. Clients and workers use a variety of information in judging clinical change. But each party is likely to use more of the information that supports its perspective, and neither party may know what criteria the other is employing. The quality and the character of information used in evaluation can be made more clinically reliable and relevant by employing similar criteria in the process of evaluation. Therefore, any procedure that helps identify the evaluative dimensions should result in more understandable assessment. Historically, research instruments have been used for this purpose to minimize error. But, historically, the treatment utility of such instruments has been questioned.

4. Stakeholders can broaden the range of evaluative inquiry. The application of predetermined or externally defined outcome criteria, such as the administration of scales and inventories, may result in limited information. Although this information may be of great research value, it may offer little for clinical evaluation in a given case. As Thyer (1991) notes, "Social workers of all theoretical orientations agree that client actions are often worthy of direct assessment" (p. 81). By utilizing client and worker definitions of problem change and goal attainment, we may not only broaden the range of evaluative criteria but also increase the "reality" of evaluation. In fact, stakeholder definitions and descriptions of problem change and goal attain- 
ment may be far more relevant to the practicing clinician than a research instrument that is reliable and valid.

5. Stakeholders are mutually educated by the fourth-generation process. All evaluations, regardless of their scientific merits, are open to criticism. It is unlikely that workers and clients always agree on clinical progress, and they are even less likely to agree on why. In fourth-generation evaluation, not only are the stakeholders involved in their own definitions of outcomes, but they are required to understand the definitions of the others. Thus, at least at a theoretical level, the evaluative criteria employed by a worker must in some way be related to those employed by the client. If they are not, the criteria should become the focus of discussion, thereby making the construction of the outcomes better.

Adopting the logic and guiding principles of fourth-generation evaluation and developmental research, we conducted a field study. It is our contention that the background of this approach provides the basic foundation for the defined purposes of the study: to help develop idiosyncratic evaluative methods and to develop a training and supervisory mechanism based on these idiosyncratic data. We have provided information on the evolution and implementation of the field study below, because it is inherently a part of the client-practitioner method of evaluation. In addition, we have presented four case examples to illustrate the clinical utility of the proposed evaluation method. These cases were selected for presentation because they depict diverse situations, and they further demonstrate the usefulness of the proposed strategy, in that the outcome "measures" are truly based on individual assessments that incorporate the perceptions of the key participants in the treatment program—worker and client.

\section{DESCRIPTION OF FIELD STUDY}

This field study was conducted in a family service agency located in a midwestern city. Full cooperation was obtained from the agency director and all workers by explaining the logic and rationale for the study. Several planning meetings were held with the workers in the agency. During these meetings, the researchers explained their general ideas to the workers, listened to suggestions made by the workers, and ironed out the procedures. The evaluation form that emerged, including the name Counseling Update and the implementation procedures, resulted from these discussions.

The workers in this agency met with new clients until they specified target problems and goals that they sought to address in the course of treatment. 
These problems and goals then became a natural focus of measurement for this study and, from the workers' perspective, were indeed factors in which they had an explicit interest. No attempt was made either to change the worker specifications of problems or to change workers' ways of monitoring progress. Thus some of the problems and goals could be stated in very broad terms ("increase satisfaction with their marriage"), and others could be highly specific ("Jimmy will brush his teeth before he goes to bed"). In other words, we accepted what the worker gave us. How the worker and client judged an increase in marital satisfaction and Jimmy's brushing behavior become the focus for evaluation.

After the problem and goal specification stage, the workers introduced the Counseling Update as part of an ongoing treatment regimen and agency data-collection procedure. This was an important and critical feature of our program, in that the gathering of information via the Counseling Update was now considered normative practice. Although the instructions on how to use the form are printed on the Counseling Update, the workers provided verbal instructions as well. In effect, this strategy generally complied with Kopp's (1988) observation that workers' attitudes toward the collection of such data plays a critical role in the development of client expectations.

At the beginning of each session, workers asked clients to rate their own perceptions of change over the past week on each of the specified problems or goals. At the end of each session, after the client's departure, workers recorded their own ratings of client progress over the past week, based on information garnered during the course of the interview, something similar to a progress note.

The decision on when to complete the forms was made by the workers and researchers. By having the client complete the Counseling Update prior to the session, their ratings could not be contaminated by what occurred during the session. On the other hand, the workers had to complete the Update after the session, because they would have little information about client change prior to the interview.

There were two clear and substantively distinct phases that emerged during the field study that are reflective of the developmental model. In Phase 1 , the workers and clients rated change on the Counseling Update, but only the workers recorded their rationales for the rating. This decision was dictated by the workers' belief that they got the information for their rating from the client anyway and to have the client write down his or her reasons would be redundant. In Phase 2, both the worker and the client recorded their rationales for change in addition to providing a rating. Phase 2 of the project was initiated when workers began to see significant disparities between the 
ratings provided by the client and their own ratings. Note that the move to Phase 2 was a data-driven decision made by the agency workers and one that was strongly supported by the researchers. The workers had learned the value of separate ratings and rationales.

Several different versions of the Counseling Update form were used during a long pretest period (roughly one year) prior to deciding on the final version. The Counseling Update is a very simple, self-anchored rating scale. The ratings take the form of points on a graph ranging from -5 to 0 to 5 . The 0 value is always the starting point for any given problem or goal and represents the beginning of treatment. Thus, regardless of the severity of a given problem at intake, it is always given the value 0 . We recognize that this strategy may result in considerable variability. Problems and goals that are defined more specifically may be more amenable to quantification than those articulated more globally. As such, the 0 level may be better defined in the former instance by the worker. However, this strategy is in line with the notion of starting where the worker is, given the absence of baseline data. From a developmental perspective, we would expect worker behaviors to change toward greater specificity over time.

Improvement in the target problem or goal is signaled by choosing a point in a positive direction. If only a small improvement is seen, a worker may choose 1 ; if a major positive change is observed, a worker may choose to record a 3 or 4 . Similarly, the amount of negative change or problem deterioration is noted by selecting a rating in the negative range. If there has been no change since the last week, the same point used in the immediately preceding session is used. In all instances, the prior week's rating serves as the base or the anchor for the new rating. A continuous rating of 5 would indicate the achievement of the desired goal.

For each entry made by the worker and client, a reason for the allocation of that particular rating is provided. In effect, the worker writes down his or her criteria for assessing change, and the client does the same. Thus each party in treatment makes public the amount of progress he or she sees in treatment as well as his or her reasons. This information serves a function related to progress notes, and therefore the data are maintained as part of the client record.

Two additional questions are posed to the worker in the Counseling Update. Both questions are intended to serve a "behavior guiding" function (Thomas, 1984). The first, "Did you discuss your rating or the client's rating on the form with the client during treatment?" hints at the inherent utility of the data for clinical purposes-a potentially relevant factor when there is disagreement between worker and client ratings and rationales. The second 
question, "How confident are you in the accuracy of your rating?" forced the worker to consider the quality of their judgments or assessments seriously. Because there is nothing to prevent the worker from looking at the client rating, a different but independent judgment from that of the client requires some thought and justification. Note that these two questions are asked only of the worker. Note also that the workers were not required to discuss the data points or their rationales with their clients. Once again, however, given our developmental approach, we anticipate that the workers will be more inclined to use this information in treatment over time.

\section{CASE EXAMPLES}

We have selected four cases to illustrate the utility of the process. Three of the four cases were seen during the initial phases of the project (Phase 1), when the worker recorded his or her rationales for change but the client did not. Thus we have no idea why a client may have given a particular rating. In all cases, several different problems were recorded and reported. For illustrative purposes, we are presenting only selected problems. In Case 1, the worker reports dramatic positive change during the course of treatment, but the client reports a worsening of the situation. In Case 2, the client reports dramatic positive change, but the worker reports little or no change.

\section{Case 1}

This case deals with an individual who is in the process of securing a divorce. The goal, "clarify questions related to divorce," is rather vague and nonspecific. According to the notes made by the worker, the attainment of this goal requires the client to carry out a variety of activities. The worker reports positive progress by virtue of the client's conducting these activities. Clearly, the client has a very different perspective. She never shows a positive change and constantly records some deterioration (see Figure 1).

Accepting the worker's rationales for the positive ratings, one is left with the impression that the worker is evaluating compliance with therapeutic instigations. The worker appears to be satisfied with progress because the client is actively engaged in a series of behaviors related to the resolution of the problem as perceived and defined by the worker. In contrast, the client appears to be simply going through the motions. She clearly indicates that the situation has not changed. Whether these differences are a function of miscommunication, lack of goal specificity, lack of attention to client feelings, or any other reason, the fact of the matter is that there is a major dif- 


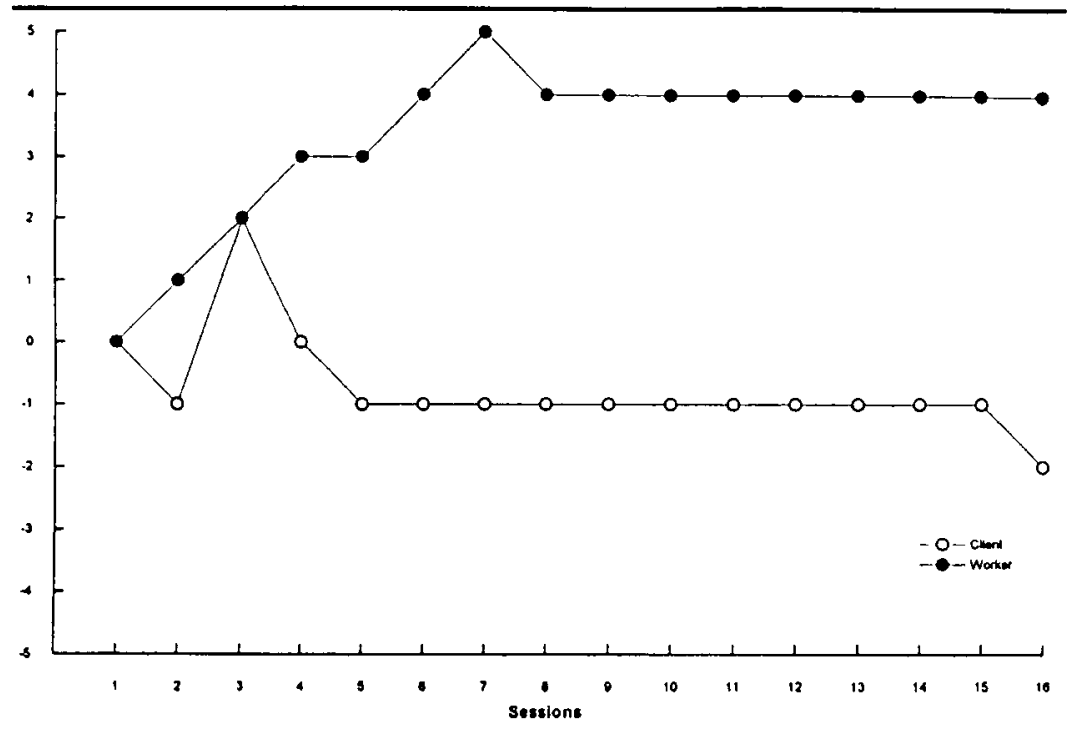

Figure 1: Clarify Questions Related to Divorce.

Session 1: Still in the process of trying to identify questions to clarify. This is a very difficult case. Session 2: She got the numbers of two police reports and called her physician for medical records. Session 3: She went to the shelter for a copy of the documentation of her injuries and had the MD sign a release for records. Session 4: She decided on a visitation schedule to request through her attorney. She also called about the whereabouts of records. Session 5: She made a telephone call to the sheriff's department to find out if her husband is on the LEIN machine. Session 6: Called child protective services regarding past abuse; requested counseling and got it through the court. Session 7: Negotiated in joint session an agreement of specific visitation for Christmas holidays. Both signed a copy. Session 8. Reports that $M$ did not follow the agreement. Got out of the car when delivering children and was 17 min late. Session 9: No agreement reached regarding telephones calls to children-tabled until later; reviewed court order. Session 10: He was on time for pickup and delivery. He did not stay in the car per agreement. Session 11: Will try one telephone call this week for $M$ to see children, and both committed to logging problems related to telephone call. Session 12: There was no opportunity for regular visitation, but he kept children for several days while she was out of town. Session 13: There has been no change because there has been no visit with father (ex-husband) since last session. Session 14: Agreed to husband picking up son and daughter to bring them to counseling. Wrote a note to school. Session 15: We worked in this session on a proposal for $M$ to mail a weekly form to $\mathrm{K}$ regarding shifts and when he would pick up children. Session 16: K \& M agreed the children would stay with $\mathrm{M}$ during his aunt's funeral and with $\mathrm{K}$ at the dinner.

ference between the worker and client about how things are going in treatment. According to the records, the case was closed when "the client decided she did not wish to participate in treatment any longer." Certainly a predictable result given the data. 


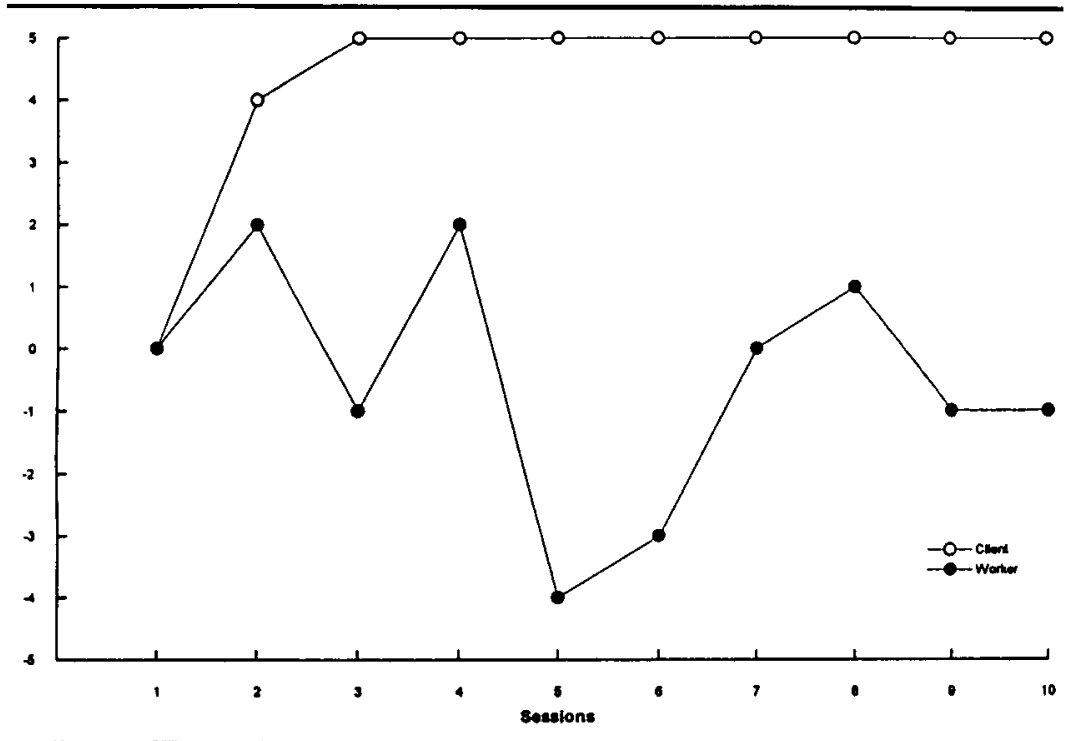

Figure 2: Increase Frequency of Sexual Intercourse.

Session 1: They had sex four times only. Session 2. They had sex nine times. Session 3: They had sex five times. Session 4: They had sex six times only. Session 5: They had sex one time. Session 6: They had sex two times. Session 7: They had sex six times. Session 8: They had sex seven times. Session 9. They had sex four times. Session 10. They had sex five times.

\section{Case 2}

This case deals with a woman who came in for marital counseling. The graph in Figure 2 depicts her recordings related to a goal identified as "increase frequency of sex." On face value, a frequency count of sexual interaction appears to be reasonably specific. It is an event that either occurs or does not occur. However, we see a disparity in the recordings of the worker and the client, although, in this instance, the client reports significant progress and the worker reports little change. Thus, despite the apparent specific nature of the goal and targeted behavior, there appears to be considerable disagreement. Once again, we are left to speculate on the reasons for the client's positive ratings. According to the records, this case was closed by mutual consent, and the closing comments read: "[Client] reports feeling very satisfied with techniques learned for negotiation, communication, and caring behaviors." Here, the worker seems to have gone along with the client, even though she reports a lack of change in the client.

Both Figure 1 and Figure 2 present findings recording important disparities between client and worker ratings suggestive of poor communication or 


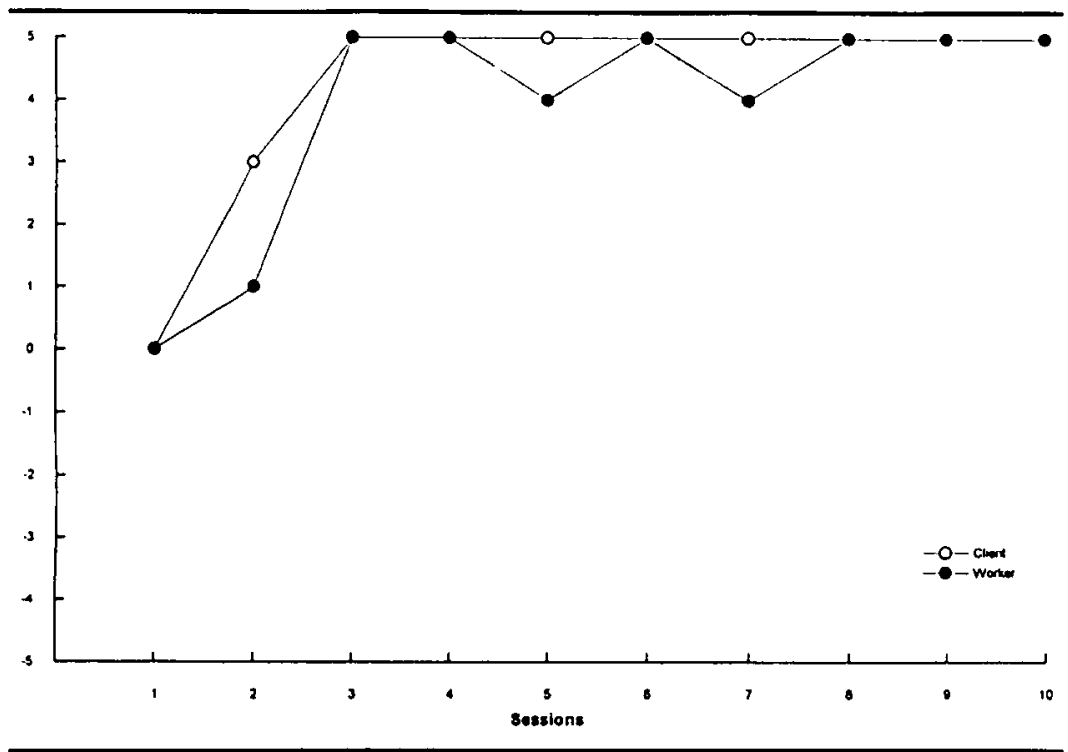

Figure 3: Increase Rachel's Staying in Bed.

NOTE: Session 1: client-none provided; worker-60\% stayed in bed. Session 2. client-Rachel has stayed in bed better; worker-stayed in bed $71 \%$. Session 3: client-Rachel understands to get everything done before going to bed; worker-stayed in bed $100 \%$. Session 4: client-Rachel has stayed in bed really well since starting this program; worker-stayed in bed $100 \%$. Session 5 : client-Rachel does well staying in bed; worker-stayed in bed $80 \%$. Session 6: client-Rachel stayed in bed well; worker-stayed in bed $100 \%$. Session 7: client-Rachel stayed in bed except for one night when she forgot to go potty; worker-stayed in bed $80 \%$. Session 8 . client-Rachel is doing good; worker-stayed in bed $100 \%$. Session 9: client-Rachel stays in bed well; worker-stayed in bed $100 \%$. Session 10. client-couldn't be better; workerstayed in bed $100 \%$.

misunderstanding. It is noteworthy that the disparity arises with two very different goals: one, very discrete, involving frequency of sex; the other, broader and more contentious, involving clarification of questions.

\section{Case 3}

This case deals with a child management problem encountered by a parent and represents a case that was seen during Phase 2 of the project. The goal is specified as "increase Rachel's staying in bed after being tucked in." This is a fairly concrete behavior that has been specified reasonably well. As seen in Figure 3, there is a high level of agreement between the worker and client on goal attainment throughout the course of intervention. However, we see a substantial difference in the way in which they explain their ratings. The 
worker uses a purely numeric and quantitative rationale. The client, in contrast, provides general qualitative impressions, with only one instance even approximating a numeric rating when she says, "Rachel stayed in bed except for one night when she forgot to go potty." Yet there is a high level of agreement between the worker and client on the attainment of the desired goal. According to the records, this case was closed by mutual consent, and the closing comments read: "Data indicate continued $100 \%$ compliance on bedtime. Client expresses gratitude for assistance given and states that she has been using child management techniques to change other child's behaviors. Reports home environment has improved significantly."

\section{Case 4}

This is a report on a marital case in which the wife is concerned about her husband's willingness to do household chores. The specified goal is to increase the husband's "helpful behaviors" around the house. This is a fairly nonspecific goal covering a broad range of behaviors. As seen in Figure 4, this case illustrates a situation in which there is a discrepancy in ratings between the worker and client at the beginning of treatment, but, over time, the two ratings converge. In addition, there appears to be greater specificity in the statements appearing toward the end of the case, suggesting a desirable trend. According to the records, this case was closed by mutual consent. No other comments were noted.

\section{DISCUSSION AND APPLICATIONS TO RESEARCH ON SOCIAL WORK PRACTICE}

The primary underlying assumption in this approach is that workers are constantly evaluating client progress and the efficacy of their interventions. Our approach offers a means by which to systematize such evaluation and to make it visible and practical. By inviting clients to rate their progress on identified problems and goals, this process allows the workers to become more cognizant of similarities and differences in their respective understanding of the problems. Similarly, by having workers share their observations with their clients graphically, clients are provided an opportunity to understand better how a worker is assessing change or judging clinical progress. When disparities exist, they provide a basis for clarifying differences or similarities in worker and client perceptions that might prove important to effective treatment. As such, they offer a means of recognizing disparities 


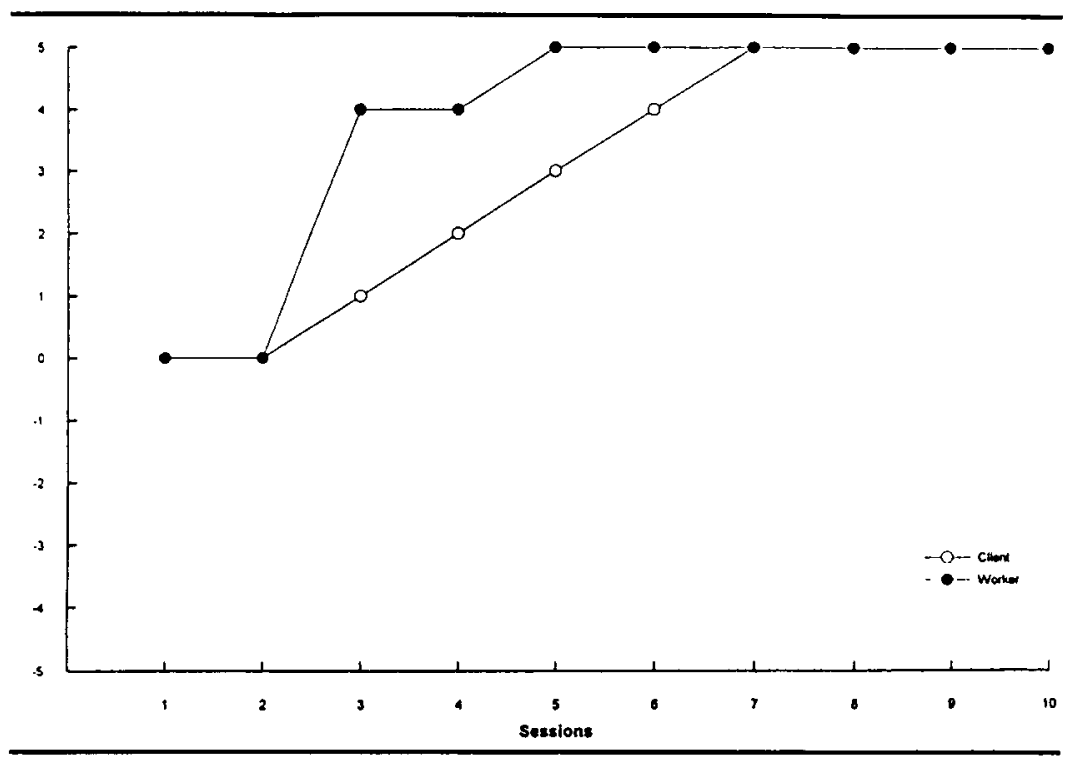

Figure 4: Increase Dean's Helping Behaviors.

Session 1: Just identified the problem. Session 2. Has started helping around the house, such as by picking up after himself. Session 3. Verbal report that he continues to be very helpful around the house. Session 4: Several helpful behaviors were recorded last week. Session 5: She reports that Dean continues to be very helpful with household chores. Session 6: Reports that she is very pleased with his helpfulness, such as vacuuming, taking care of baby, and picking up. Session 7: Reports that Dean continues to be very helpful with the baby and with household chores. Session 8. She says that husband continues to be very helpful around the house. Session 9. Husband continues to be very helpful around the house, and she is very pleased. Session 10. He is still being very helpful, and she is very pleased with that.

quickly, so as to improve internal consistency and maximize treatment progress within cases.

In general, we view the processes described above as a form of selfmonitoring. The client monitors changes in his or her problems and goals on a weekly basis, and the worker monitors his or her own perceptions of changes in the client's performance. This type of weekly retrospection demonstrating an overall data pattern may be as accurate as daily ratings (e.g., Broden, Hall, \& Mitts, 1971; Lipinski, Black, Nelson, \& Ciminero, 1975; Nelson, Lipinski, \& Black, 1975). In addition, Kazdin (1974) has argued that the discussion of data obtained from self-monitoring may enhance the change process. The client and worker rating forms serve as catalysts for dialogue and clarification of goals between worker and client to enhance mutual understanding. 
What distinguishes the processes described in this article from the general self-monitoring literature is that it is viewed as a complementary procedure. Virtually all of the self-monitoring literature addresses issues related to the collection of data by the client. In fact, Kopp (1988), upon reviewing the self-monitoring literature, notes that "the belief that one can change may be enhanced through the worker empowering the client to self-record. The commitment to monitor is a commitment to act on a presenting issue, and implies a commitment to change" (p. 15). Although this may reveal a commitment to change on the part of the client, it does not explicitly demonstrate a commitment on the part of the worker. By having the worker record data that parallel the data collected by the client, the notion of empowering the client has been further reinforced. Now, not only is the client in a position to evaluate his or her own behavior, but the client is also in a better position to clarify issues with the worker by comparing ratings and rationales. The sharing of such information should lead to greater mutuality in the treatment process and, in our view, greater empowerment and commitment on the part of the client and a mutual education process as suggested by Guba and Lincoln (1989).

For instance, if a worker and client arrive at an agreed-upon goal, but after several sessions the worker notices that the client is graphing a decrement and the worker is graphing an improvement, this might suggest a variety of possibilities. The client or worker may have misconstrued the dimensions of the problem to be addressed and may need to clarify this matter further to ensure effective cooperation; the client's criteria for measuring improvement may have shifted or drifted from those originally agreed upon, unknown to the worker; or the worker may not have been made privy to, may have misunderstood, or may have misinterpreted the importance of factors influential in the client's judgment. The additional information provided by the graphs and client rationales could serve as an impetus and a basis for dialogue in any of these situations.

Beyond the worker and client, this approach has the potential to be useful in supervisory and administrative contexts. It offers supervisors an additional vehicle for clinical supervision, in that it provides a means of honing problem definitions, increasing assessment specificity, and improving intervention efficacy, possibly reducing treatment time. For example, the graphic representations of differential ratings reported in Figures 1 and 2 offer a distinct opportunity for supervision. In addition, this methodology offers the supervisor a means of detecting potential difficulties with regard to communication between client and practitioner, such as use of different types of criteria to measure progress. It is possible, for example, that clients and workers may 
at times be mutually engaged in addressing a "wrong" or tangential problem. Given the types of data being collected, supervisors may be in a better position to question such activities and even discuss the potential pitfalls that may emerge when one relies purely on client input.

For the administrator, these graphic representations and rationales provide a generic indicator that may be informative for understanding trends in client utilization of services and for assessing change. The administrator may discover a relationship between the types of identified problems, the length of treatment between or across workers, and client drop-out rate. This type of information may prove useful in assigning cases to particular workers or in anticipating the duration of treatment. This model provides all concerned with a technique that allows an agency or individual to evaluate outcome efficacy by averaging rating points across time. For instance, one could average the last three ratings as a basis for determining outcome, thereby controlling to some extent "halo effects," which could occur when data are collected only at posttreatment.

Recent years have seen the entry of computerized monitoring systems. For example, Benbenishty and Ben-Zaken (1988) developed a computeraided process for monitoring task-centered family practice. This monitoring system includes a clinical rating scale to assess progress regularly, as well as a goal attainment scale. Gingerich, Schirtzinger, and Hoffman (1991) developed a program called MY ASSISTANT to help in case management. This program allows the worker to register continuous progress and to enter relevant progress notes. Neither program, however, complies with the basic premise of the Counseling Update-namely, the direct recording of progress by both the client and worker. In addition, there are questions related to innovation diffusion, such as user attitude toward the innovation and relative costs and benefits, that have yet to be answered with computerization. In fact, Benbenishty and Ben-Zaken (1988) noted that "the process of computerized monitoring of practice puts heavy demands on social workers" (p. 9).

In summary, we are of the opinion that an empirical practice model is desirable and has far more to offer than its detractors would lead us to believe. It has been demonstrated to apply equally well across a variety of problems and goals, whether individual, marital, or child management, and, thus, to be consonant with service objectives in the practice setting. It allows for client perceptions, subjectivity, active involvement, psychological state, cultural and ethnic background, environmental and social conditions, and current needs and unique goals. We see the flexible monitoring approach as a developmental methodology, one that could pave the way to the generation of more appropriate measures and alternate designs. It involves minimal time and 
intrusion on the therapeutic process, while offering a potential catalyst for increased consistency in intervention assessment and subsequent reliability and validity. By addressing a treatment issue in this fashion, we are hoping to learn how to tailor research principles to maximize the efficacy of the practice process.

Viewed as pure developmental research, the goal of this endeavor is to improve worker consistency in the use of stable evaluation criteria for a given problem. If this occurs, then the design and development of this intervention will have been a success. If not, we will have more information with which to modify our design for a more effective intervention. Although an empirical practice model is highly desirable, the methodology described above offers a necessary initial step. In effect, the adage "Start where the client is" may be asserting too much; perhaps it should read "Start where the worker thinks where the client is"-when it comes to the assessment of treatment effects.

\section{REFERENCES}

Barlow, D. H., Hayes, S. C., \& Nelson, R. O. (1984). The scientist practitioner: Research and accountability in clinical and educational settings. New York: Pergamon.

Benbenishty, R., \& Ben-Zaken, A. (1988). Computer-aided process of monitoring task-centered family interventions. Social Work Research \& Abstracts, 24, 7-9.

Bloom, M., \& Fischer, J. (1982). Evaluating practice: Guidelines for the accountable professional. Englewood Cliffs, NJ: Prentice-Hall.

Blythe, B. J., \& Briar, S. (1985). Developing empirically based models of practice. Social Work, $30,483-488$.

Briar, S. (1977). Incorporating research into education for clinical practice in social work: Toward a clinical science in social work. In A. Rubin \& A. Rosenblatt (Eds.), Sourcebook on research utilization (pp. 132-140). New York: Council on Social Work Education.

Broden, B., Hall, R. V., \& Mitts, B. (1971). The effect of self-recording the classroom behavior of two eighth-grade students. Journal of Applied Behavior Analysis, 4, 191-199.

Brunner, I., \& Guzman, A. (1989). Participatory evaluation: A tool to assess projects and empower people. International Innovations in Evaluation Methodology: New Directions for Program Evaluation, 42, 9-18.

Campbell, J. A. (1988). Client acceptance of single-system evaluation procedures. Social Work Research \& Abstracts, 24, 21-22.

Conte, J. R., \& Levy, R. L. (1980). Problems and issues in implementing the clinical-research model of practice in educational and clinical settings. Journal of Education for Social Work, $16,60-66$.

Dolan, M. M., \& Vourlekis, M. M. (1983). A field project: Single-subject design in a public social service agency. Journal of Social Service Research, 6, 29-43.

Gambrill, E. D., \& Barth, R. P. (1980). Single-case study designs revisited. Social Work Research \& Abstracts, 16, 15-20.

Gill, S. J., \& Zimmerman, N. R. (1990). Racial/ethnic and gender bias in the courts: A stakeholder-focused evaluation. Evaluation Practice, 11, 103-108. 
Gingerich, W. J. (1984). Generalizing single-case evaluation from classroom to practice. Journal of Education for Social Work, 20, 74-82.

Gingerich, W. J. (1990). Rethinking single-case evaluation. In L. Videka-Sherman \& W. J. Reid (Eds.), Advances in clinical social work research (pp. 11-24). Silver Spring, MD: National Association of Social Workers Press.

Gingerich, W. J., Schirtzinger, J., \& Hoffman, D. L. (1991). MY ASSISTANT: Design and development of a computer-assisted case management system. Paper presented at the HUSITA-2 Conference, New Brunswick, NJ.

Guba, E. G., \& Lincoln, Y. S. (1989). Fourth generation evaluation. Newbury Park, CA: Sage.

Hayes, S. C., Nelson, R. O., \& Jarrett, R. B. (1987). The treatment utility of assessment. Ann Arbor, MI: Institute for Social Research.

Heineman, M. B. (1981). The obsolete scientific imperative in social work research. Social Service Review, 55, 371-397.

Howe, G. S. (1974). Casework self-evaluation: A single subject approach. Social Service Review, $48,1-24$.

Jayaratne, S. (1991). Clinical significance: Problems and new developments. In L. VidekaSherman \& W. J. Reid (Eds.), Advances in clinical social work research (pp. 271-285). Silver Spring, MD: National Association of Social Workers Press.

Jayaratne, S., \& Levy, R. L. (1979). Empirical clinical practice. New York: Columbia University Press.

Kagle, J. D. (1983). Using single-subject measures in practice decisions: Systematic documentation or distortion? Arete, 7, 1-9.

Kazdin, A. E. (1974). Reactive self-monitoring: The effects of response desirability, goal setting, and feedback. Journal of Consulting and Clinical Psychology, 42, 704-716.

Kirk, S. (1986). The chronically mentally ill and social-problem research. In J. P. Bowker \& A. Rubin (Eds.), Studies on chronic mental illness: New horizons for social work researchers (pp. 187-203). Washington, DC: Council on Social Work Education.

Kopp, J. (1988). Self-monitoring: A literature review of research and practice. Social Work Research \& Abstracts, 24, 8-20.

Larsen, D. L., Attkisson, C. C., Hargreaves, W. A., \& Ngyen, T. D. (1979). Assessment of client/patient satisfaction: Development of a general scale. Evaluation and Program Planning, 2, 197-207.

Levy, R. L., \& Olson, D. G. (1979). The single-subject methodology in clinical practice: An overview. Joumal of Social Service Research, 3, 25-49.

Lipinski, D. P., Black, J. L., Nelson, R. O., \& Ciminero, A. R. (1975). The influence of motivational variables on the reactivity and reliability of self-recording. Joumal of Consulting and Clinical Psychology, 43, 637-646.

Mutschler, E. (1984). Evaluating practice: A study of research utilization by practitioners. Social Work, 29, 332-337.

Nelsen, J. C. (1981). Issues in single-subject research for nonbehaviorists. Social Work Research \& Abstracts, 20, 3-10.

Nelson, R. O., Lipinski, D. P., \& Black, J. L. (1975). The effects of expectancy on the reactivity of self-recording. Behavior Therapy, 6, 337-349.

Patton, M. Q. (1986). Utilization-focused research. Newbury Park, CA: Sage.

Richey, C. A., Blythe, B. J., \& Berlin, S. B. (1987). Do social workers evaluate their practice? Social Work Research \& Abstracts, 23, 14-20.

Robinson, E.A.R., Bronson, D., \& Blythe, B. J. (1988). An analysis of the implementation of single-case evaluation by practitioners. Social Service Review, 62, 285-301. 
Rothman, J. (1980). Social R\&D: Research and development in the human services. New York: Columbia University Press.

Russell, M. N. (1990). Consumer satisfaction: An investigation of contributing factors. Journal of Social Service Research, 13, 43-56.

Saleeby, D. (1979). The tension between research and practice: Assumptions of experimental paradigm. Clinical Social Work Journal, 7, 267-284.

Stake, R. (1975). Evaluating the arts in education: $A$ responsive approach. Columbus, $\mathrm{OH}$ : Merrill.

Thomas, E. J. (1975). Uses of research methods in interpersonal practice. In N. A. Polansky (Ed.), Social work research: Methods for the helping professions (pp. 254-283). Chicago: University of Chicago Press.

Thomas, E. J. (1978). Research and service in single-case experimentation: Conflicts and choices. Social Work Research \& Abstracts, 14, $20-31$.

Thomas, E. J. (1984). Designing interventions for the helping professions. Beverly Hills, CA.: Sage.

Thomas, E. J. (1990). Modes of practice in developmental research. In L. Videka-Sherman \& W. J. Reid (Eds.), Advances in clinical social work research (pp. 202-217). Silver Spring, MD: National Association of Social Workers Press.

Thyer, B. A. (1991). Guidelines for evaluating outcome studies on social work practice. Research on Social Work Practice, 1, 76-91.

Tripodi, T. (1991). Attribution theory and clinical significance. In L. Videka-Sherman \& W. J. Reid (Eds.), Advances in clinical social work research (pp. 286-289). Silver Spring, MD: National Association of Social Workers Press.

Tripodi, T., \& Epstein, I. (1980). Research techniques for social workers. New York: Columbia University Press.

Welch, G. J. (1983). Will graduates use single-subject designs to evaluate their casework practice? Journal of Education for Social Work, 19, 42-46.

Witkin, S. L. (1991). Empirical clinical practice: A critical analysis. Social Work, 36, 97-192.

Wodarski, J. S. (1981). The role of research in clinical practice: A practical approach to the human services. Baltimore, MD: University Park Press. 